and with the publication space of most geographical and closely related journals almost halved as a result of war-time restrictions and rising costs, the emergence of a new journal to cope with the increasing flow of research material now available is not surprising. Geographical Studies has been founded very largely by younger geographers to meet this need. The first number, running to some forty thousand words, is well produced apart from an over-reduction of some of the maps and diagrams: it includes research articles from six contributors ranging over a wide field, and also contains notes of geographical interest. Prof. F. K. Hare deals with the boreal conifer zone, while Prof. P. R. Crowe attempts, in an article on the effectiveness of precipitation, a graphical analysis of Thornthwaite's climatic classifications. Dr. G. J. Butland describes the changing land occupancy in southern Chile, and Dr. W. R. Mead, in an article on the language of place, draws some interesting conclusions from a study of two Finnish dictionaries. Geomorphology is represented in an ingenious article from Miss Alice Coleman on the use of the height-range diagram in morphological analysis, and in conclusion J. H. Hubbard contributes some new data on the rainfall of the Gold Coast. It is proposed to issue Geographical Studies at least once and possibly twice a year initially. The journal is published from Birkbeck College, Malet Street, London, W.C.l (price 10s.), and inquiries should be addressed there to Dr. G. H. Dury.

\section{British Mathematical Colloquium}

The sixth British Mathematical Colloquium was held at Cambridge during April 6-8. Among the hundred and seventy members were Prof. A. Zygmund, at present working in Cambridge, and Prof. L. Schwartz, of Paris, who attended as foreign guest of honour. The first day was devoted to algebra, and the following papers were read: Dr. D. Rees, an aspect of multiplicative ideal theory; Dr. W. Ledermann, some recent work on group characters ; Mrs. H. Neumann, Hopf's problem; Dr. C. H. Dowker, dimension of metric spaces. The day devoted to analysis included papers by Prof. Zygmund on Hilbert's transform and its generalizations, Mrs. D. Stone on measure algebras, Dr. H. G. Eggleston on extremal geometrical problems, and Prof. Schwartz on distributions and applications to partial differential equations of hyperbolic type. The geometry (third day) discussed was chiefly algebraic: Prof. J. G. Semple, on enumerative geometry and the method of degenerate collineations ; Dr. D. B. Scott, on self-correspondences on algebraic curves and surfaces; Dr. J. A. Todd, on canonical systems on algebraic varieties; Prof. D. G. Northcott, on some local and global aspects of the foundations of geometry. The 'splinter groups' worked with enthusiasm during the intervals available from the main programme, and exchanged much information on problems now being actively investigated. On the afternoon of April 7, a visit was paid to the University Mathematical Laboratory. It is hoped to hold a seventh colloquium in 1955, at the University College of the South-West, Exeter.

\section{Wittgenstein's Philosophical Views}

Is January 1929, Prof. Ludwig Wittgenstein returned to Cambridge after an absence of more than fifteen years. His return was largely due to the influence of Prof. F. P. Ramsey, who described him as "a philosophic genius of a different order from anyone else I know". Wittgenstein began lecturing in 1930 and continued until 1933. Records of the lectures and subsequent discussions were kept by Prof. G. E. Moore, who has prepared an account of them in a recent issue of Mind (63, No. 249; January 1954). Among the topics considered were some general questions about language, some special questions in the philosophy of logic and mathematics, as well as behaviourism, solipsism, idealism, realism, "the grammar of the word 'God' and ethical and resthetic statements". The journal also contains a detailed critical notice of Wittgenstein's book "Philosophical Investigations" by P. F. Strawson.

\section{Leicester Museums and Art Gallery: Annual Report for 1952-53}

THE forty-seventh annual report of the City of Leicester Museums and Art Gallery for the year April 1, 1952-March 31, 1953 (pp. 44+4 plates; 1953), reflects the steady and continued achievement of this institution. It is an attractive, illustrated production and records faithfully the consolidation that has taken place after the period of considerable reorganization undertaken since the end of the Second World War. The year has been one of close and friendly liaison with local cultural societies, and much extra-mural work has been accomplished in collaboration with the appropriate department in the University College. This means that the Museum buildings are in use on most evenings during the week. The outstanding acquisition of the year was a fine overmantel and oak panelling from Ragdale Hall, Leicestershire, made possible through the generosity of the trustees of the Friends of the Museum Fund.

\section{Non-Destructive Testing Group of the Institute of Physics: Meeting in Birmingham}

WrTH the appearance of new techniques for proving or sorting materials and components, some of which are complementary to radiography, the Industrial Radiology Group of the Institute of Physics has changed its name to the Non-Destructive Testing Group, and, under its new title and with extended terms of reference, the Group is holding a summer meeting, which will be on a wider field of physical methods of non-destructive testing than on previous occasions. The meeting will be held in the Chancellor's Hall, University of Birmingham, during July 7-10 and will be open both to members and non-members of the Group, subject to the limit of lecture-room capacity of about three hundred persons. Prof. A. J. Murphy, professor of industrial metallurgy in the University of Birmingham, will give an address on the evening of July 7 , and on the succeeding three days six papers will be presented dealing with the following topics: isotope techniques; image intensifiers; diffraction mottling; theory and application of electrical and magnetic methods of non-destructive testing; propagation of elastic waves in solids; and selected topics in ultrasonic testing. Abstracts of the contributed papers will be circulated shortly before the meeting, and the proceedings will be reported in the bulletin of the Group and in the British Journal of Applied Physics. Enrolment forms (to be returned by May 31) and further information can be obtained from the Deputy Secretary, Institute of Physics, 47 Belgrave Square, London, S.W.1. 